from 15 to $20 \mathrm{sec}$. The interval between the shock and click ranged from 5 to 10 sec. (5) Group CS received 30 pairings of the click and the shock. The interval between the click and the shock was always $.5 \mathrm{sec}$. The interval between successive click-shock pairings ranged from 10 to $50 \mathrm{sec}$.

The above procedure was followed by 8 days of extinction with the dipper activated; that is, every leverpress produced both the unloaded dipper and the distinctive click. Each of the eight extinction sessions was $15 \mathrm{~min}$.

\section{RESULTS}

An analysis of variance was performed on the mean number of responses per $S$ for the last day of acquisition. No significant differences were found $(F=0.173$, $\mathrm{df}=4 / 55, \mathrm{p}>.05)$. Since $\mathrm{Ss}$ were assigned to groups on the basis of their first extinction (nonclick), it is not surprising that the terminal rate of responding (Day 4 of extinction) was very similar for the five groups $(F=0.443, \mathrm{df}=4 / 55, \mathrm{p}>.05)$. Ss in all groups averaged less than 12 leverpresses on the last day of extinction without the water dipper.

The mean of the cumulative responses emitted by the five groups during the 8 days of extinction that produced the empty dipper is shown in Fig. 1. Groups NS and $C$ showed a typical decrease in response rate as extinction progressed. Groups S, SC, and CS, however, show virtually no responding on the first day of extinction, with an initial increase in response rate during extinction, which is subsequently followed by a decrease in response rate. Analysis of variance of the mean response output for each group during the 8 days of extinction shows a significant difference among the groups $(F=6.515, \mathrm{df}=4 / 55, \mathrm{p}<.01)$.

The Newman-Keuls test was used to determine the mean differences that were significant. Differences between Groups C and $\operatorname{CS}[a=4, f=55, Q(.01)=5.6]$, NS and $\operatorname{CS}[\mathrm{a}=4, \mathrm{f}=55, \mathrm{Q}(.01)=5.1]$, and NS and $S C[a=4, f=55, Q(.05)=4.0]$ were significant. The difference between Groups S and SC fell short of significance $[\mathrm{a}=3, \mathrm{f}=55, \mathrm{Q}(.05)=3.0]$.

\section{DISCUSSION}

Assigning Ss to groups on the basis of their extinction patterns during extinction sessions without the secondary reinforcer insured that $\mathrm{Ss}$ had a low response rate before the final stages of the study were initiated. Thus, responses that produced the secondary reinforcer in the last phase of the study were in large part determined by the presence of the secondary reinforcer, rather than high resistance to extinction for the primary reinforcer. All Ss produced less than 12 responses on the last day of nonclick extinction. This supports the contention that the eight subsequent days of secondary reinforcement extinction were sufficient to differentiate between temporary response suppression and a relatively permanent decrease in responding. The data from the groups experiencing shock between the two extinction sessions suggests response suppression had some effect on the early extinction sessions. Later extinction sessions for the shock groups produced the more typical decrease in response rate across extinction sessions. This decrease, coupled with the low terminal rate of responding for $S s$ in all groups at the end of the second phase of extinction, implies that additional extinction sessions would not have changed the relative number of responses in the five experimental groups.

It is interesting to note that all groups receiving shock between the first and second extinction produced fewer extinction responses than groups receiving no shock. In addition, both groups that experienced the click and the shock between the extinction sessions (CS and SC) had lower response rates than groups that experience only one of the stimuli (C or $\mathrm{S}$ ) during the intermediate phase. Pairing the click and the shock produced fewer responses in the final extinction session when the pairings were those of a typical forward classical-conditioning paradigm. It must be noted, however, that the only statistically significant differences occurred between groups that received no shock and groups that received shock between the two kinds of extinction; i.e., the statistically significant differences were between Groups NS and CS, NS and SC, and $\mathrm{C}$ and $\mathrm{SC}$.

\section{REFERENCES}

ESTES, W. \& SKINNER, B. F. Some quantitative properties of anxiety. Journal of Experimental Psychology, 1941, 29, 390-400.

EVANS, W. Producing cither positive or negative tendencies to a stimulus associated with shock. Journal of the Experimental Analysis of Behavior, 1962, 5, 335-337.

KELLEHER, R. Schedules of conditioned reinforcement during experimental extinction. Journal of the Experimental Analysis of Behavior, 1961, 4, 1-5.

MARX, M. Resistance to extinction as a function of continuous or intermittent presentation of a training cue. Journal of Experimental Psychology, 1958, 56, 251-255.

ROZEBOOM, w. Secondary extinction of lever-pressing behavior in the albino rat. Journal of Experimental Psychology, 1957, 54, 280-287.

ZIMMERMAN, D. Sustained performance in rats based on secondary reinforcement. Journal of Comparative \& Physiological Psychology, $1959,52,353-358$.

\title{
Atypical effects of electroshock on emotionality in rats*
}

\author{
MARTIN E. HAHN, BRUCE JOHN MORRISON, EDWARD C. SIMMEL, \\ and CONNIE J. HARRIS \\ Miami University, Oxford, Ohio 45056
}

The present study examines a unique property of shock, i.e., the absence of a clearly perceivable source of the stimulus. Twenty-four male and female Sprague-Dawley rats were divided into three groups: object alone, shock alone, and shock plus object. Using three open-field measures of emotionality, it was found that the group shocked without an object present was significantly more emotional than the group shocked with an object present or the group presented with the object only.

Electroshock has been the most widely used stressful stimulus in many areas of psychological investigation. Shock, however, may have some undesirable and long-term effects. Solomon, Kamin, \& Wynne (1952), for example, demonstrated that shock-induced fear, once acquired, could elicit avoidance behavior over long periods of time and that both fear and avoidance behavior were not susceptible to standard extinction procedures. Furthermore, Walters \& Rogers (1963)

* Reprint requests should be addressed to Martin E. Hahn, Department of Psychology, State University of New York, Binghamton, N.Y. 13901 . found that previous exposure to an intense shock increased the suppressive effects of the punishment in a situation occurring 1 year after the initial shock.

Most studies employing shock make the implicit assumption that it is typical or representative of noxious stimuli in general, and it is used as the noxious stimulus of choice primarily because of the degree of control that can be exerted on its administration. There are, however, at least two unique properties of electroshock that may result in differences in behavior from those resulting from other forms of noxious stimuli that do not share these 
Table 1

Average Number af Responses and Significant Differences for Movement, Rearing, and Freezing

\begin{tabular}{|c|c|c|c|c|c|c|c|c|c|}
\hline & \multicolumn{3}{|c|}{ Xumber of Lines Crossed } & \multicolumn{3}{|c|}{ Number of Rearings } & \multicolumn{3}{|c|}{ Number of lireezings } \\
\hline & $\begin{array}{c}\text { Bulldozer } \\
\text { Only }\end{array}$ & $\begin{array}{c}\text { Shook } \\
\text { and } \\
\text { l3alkdoser }\end{array}$ & $\begin{array}{c}\text { Shock } \\
\text { Only }\end{array}$ & $\begin{array}{c}\text { Bulldozer } \\
\text { Only }\end{array}$ & $\begin{array}{c}\text { Shock } \\
\text { and } \\
\text { Bulldozer }\end{array}$ & $\begin{array}{c}\text { Shock } \\
\text { Only }\end{array}$ & $\begin{array}{c}\text { Bulldozer } \\
\text { Only }\end{array}$ & $\begin{array}{c}\text { Shock } \\
\text { and } \\
\text { Bulldozer }\end{array}$ & $\begin{array}{l}\text { Shock } \\
\text { Only }\end{array}$ \\
\hline $\begin{array}{l}\text { Hale } \\
\text { lemale } \\
\text { Total }\end{array}$ & $\begin{array}{l}39.50 \\
79.25 \\
59.37\end{array}$ & $\begin{array}{l}26.50 \\
49.50 \\
38.00\end{array}$ & $\begin{array}{r}8.00 \\
27.00 \\
17.50\end{array}$ & $\begin{array}{l}22.00 \\
31.00 \\
26.50\end{array}$ & $\begin{array}{l}13.00 \\
28.75 \\
20.87\end{array}$ & $\begin{array}{r}9.50 \\
14.25 \\
11.87\end{array}$ & $\begin{array}{r}11.50 \\
4.00 \\
7.75\end{array}$ & $\begin{array}{l}31.50 \\
11.75 \\
21.62\end{array}$ & $\begin{array}{l}70.25 \\
35.25 \\
52.75\end{array}$ \\
\hline $\begin{array}{l}\text { Duncan's } \\
\text { Multiple } \\
\text { Range on } \\
\text { Total* }\end{array}$ & + & + & + & & - & 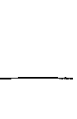 & $\ldots$ & 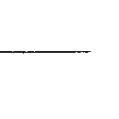 & + \\
\hline
\end{tabular}

*Mcans not underscored by: the sane line are significantly different at the 05 level.

properties. These are: (1) the sudden onset of the stimulus and (2) the absence of a perceivable source of the stimulus. In a typical paradigm employing shock, the shock has an extremely sudden onset when compared to a more natural stresser, such as the approach of a predator. Also, the shock arrives at the body of the animal through a previously harmless floor or via electrodes placed somewhere on the body of the animal.

It is this first property of shock, i.e., its lack of association with an object, which is the subject of this study.

\section{SUBJECTS}

The 24 Sprague-Dawley albino rats at 60 days of age were divided into three groups of eight, each group including four males and four females.

\section{PROCEDURE}

At the time of running, each $\mathrm{S}$ was fitted with a pair of round electrodes which were placed on the skin of his shaved back with the aid of surgical tape.

Each $\mathrm{S}$ in the object-no-shock group was placed in the end of the shock box $(18 \times 100 \times 43 \mathrm{~cm})$ opposite the end in which the bulldozer rested. After a 10-sec accommodation period, the bulldozer was pushed, via the rod, at a constant rate by the $\mathrm{E}$ toward the $\mathrm{S}$. The bulldozer was stopped for $1 \mathrm{sec}$ and was returned to its original position in another $7 \mathrm{sec}$.

Each $\mathrm{S}$ in the shock-plus-object group was treated similarly, except that an electric shock $(.25 \mathrm{~mA}, 1 \mathrm{sec}$ from a CJA stimulator) was delivered through the electrodes at the time that the toy bulldozer $(16 \times 25 \times 15 \mathrm{~cm})$ was completing its approach toward the $\mathrm{S}$.

The Ss in the shock-only group were placed in the treatment box from which the bulldozer had been removed. The time sequences used in the previous treatments were repeated so that the Ss were shocked $17 \mathrm{sec}$ after being placed in the apparatus and removed after another 17-sec period to be placed in the open field.

After a waiting period of $10 \mathrm{sec}$, all $\mathrm{Ss}$ were removed from the apparatus and electrodes and placed in the open field for
$3 \mathrm{~min}$. The open field was a $200 \times 200 \times 100 \mathrm{~cm}$ black box, the floor of which was divided into 16 equal squares.

\section{RECORDING AND ANALYSIS}

During the 3-min observation period in the open field, an Esterline-Angus event recorder recorded the occurrence and duration of the following variables: (1) center entry $-S$ is in a square that does not have a wall along its border; (2) corner occupancy $-S$ is in one of the four corner squares; (3) movement-the number of lines $S$ crossed; (4) rearing--either against a wall or free rearing; (5) grooming; (6) freezing-S spends more than approximately $5 \mathrm{sec}$ crouching in an immobile position; (7) defecation.

\section{EMOTIONALITY CORRELATES}

From inspection of the intercorrelations of the behavioral indices, two response patterns emerged. One pattern was characterized by short length of time in corner occupancy, high number of squares entered, high number of times standing, high number of center entry, short length of time freezing, and long length of time grooming. This was operationally defined as low emotionality, which conforms to previous studies (Morrison, 1967; Stern, Winokur, Eisenstein, Taylor, \& Sly, 1960) and the observation of the E. High emotionality was indicated by the opposite.

\section{EXPERIMENTAL CONDITIONS}

Table 1 presents those behavioral variables having a significant treatment main effect on a 2 by 3 (Sex by Treatment) analysis of variance. Differences between experimental conditions were then tested with a Duncan multiple range test using a 5\% level of significance. There were no significant Sex by Treatment interactions for any of these variables. The behavioral variables of grooming, center, and corner were not included, as there were no significant main effects of treatment or of Sex by Treatment. Defecation was not analyzed due to its nonoccurrence.

Female Ss crossed a greater number of lines than did male $\mathrm{Ss} \quad(\mathrm{F}=13.15$, $\mathrm{df}=1 / 16, \mathrm{p}<.01)$. This conforms to the findings of Hitchcock (1925), Munn (1950), and Simmel et al (1965).

$\mathrm{S} s$ in the shock-only condition showed the greatest emotionality (least movement and rearing and the greatest amount of freezing). Ss in the shock-plus bulldozer showed less emotionality than did shock-only Ss and more emotionality than did Ss that were not shocked.

CONCLUSION

What this study has demonstrated is that shock, delivered from a nondiscriminable source, is more emotion producing than the same shock delivered in the presence of an object. The present authors wish to suggest an explanation for this finding and also to relate the findings to the use of shock as an aversive stimulus.

When an animal is shocked with an object present, the object may come to serve as a cue for pain. When this animal is placed in the open field, the object (cue for pain) is not present in this situation and the animal's emotional arousal is reduced. Conversely, the animal shocked with no object present has no obvious cue for pain in the situation. When it is placed in the open field, its emotional arousal is not reduced because the previously occurring pain might recur from any source.

The authors construe the present results to elucidate a problem with shock as an aversive stimulus, since it is usually delivered without a clearly discriminable source. Those Es who employ shock should control for its means of delivery if the effects of that shock on behavior are being investigated.

\section{REFERENCES}

HITCHCOCK, F. A. Studies in vigor. V. The comparative activity of male and female albino rats. American Joumal of Physiology, 1925 $75,205-210$.

MORRISON, B. J. An analysis of the group testing and group housing effects upon rat emotionality. Unpubjished doctoral dissertation, Northwestern University, 1967. MUNN, N. L. Handbook of psychological research on the rat. Boston: Houghton Mifflin, 1950.

SIMMEL, E. C., CHENEY, J. H., \& LANDY, E. E. Visual vs locomotor response effects on satiation to novel stimuli: A sex difference in rats. Psychological Reports, 1965, 16, 893-896.

SOLOMON, R. L., KAMIN, L. J., \& WYNNE, L. C. Traumatic avoidance learning: The outcome of several extinction procedures with dogs. Journal of Abnormal \& Social Psychology, 1953, 48, 291-302.

STERN, J. A., WINOKUR, G., EISENSTEIN, A. TAYLOR, R., \& SLY, M. The effect of group vs individual housing on behavior and physiological responses to stress in the albino rat. Journal of Psychosomatic Research, 1960 , 4, 185-190.

WALTERS, G. C., \& ROGERS, J. V. Aversive stimulation of the rat: Long-term effects on subsequent behavior. Science, 1963, 142, $70-71$. 